\title{
Bei anhaltenden Magen-Darm-Beschwerden Bluttest veranlassen
}

Hinter vermeintlichen Reizdarmsymptomen wie Durchfall, Blähbauch und abdominellen Schmerzen kann auch einmal eine Zöliakie stecken. Diese Autoimmunerkrankung lässt sich leicht durch einen Bluttest und eine Magenspiegelung nachweisen und durch eine lebenslange glutenfreie Kost gut behandeln.

Mit einer Prävalenz von 0,5$1,5 \%$ ist die Zöliakie keine seltene Erkrankung, erklärte Prof. Dr. Martin Storr, Gastroenterologe am MVZ Gauting. Sie ist Folge einer genetisch determinierten fehlgerichteten Immunantwort auf das in vielen Getreidesorten enthaltene Klebereiweiß Gluten mit Kreuzreaktion gegen das Enzym Gewebetransglutaminase (tTG) und gegen das Hüllbindegewebe der glatten Dünndarmmuskulatur (Endomysium, $E M)$. Die Immunreaktion führt letztlich zur Entzündung und Zottenatrophie der Dünndarmmukosa.

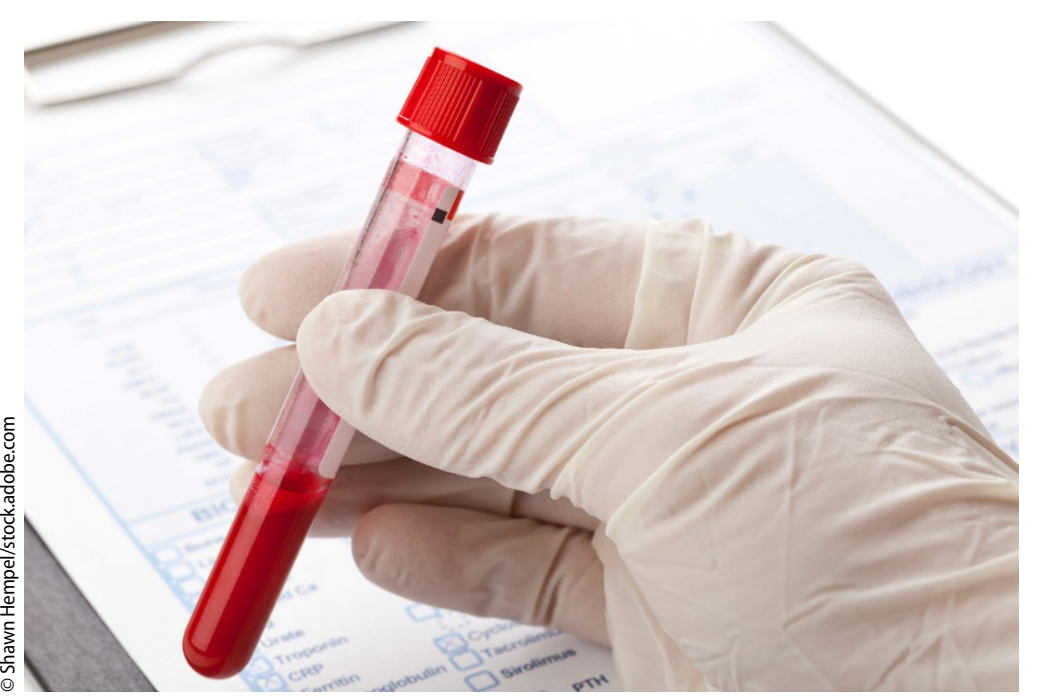

absorption wichtiger Vitamine, Mineralstoffe und Spurenelemente.

Zantl empfiehlt eine ZöliakieDiagnostik bei gastrointestinalen Beschwerden, die länger als sechs Wochen bestehen, aber auch bei anderen unklaren Symptomen. Dafür genügt zunächst eine Blutuntersuchung mit Bestimmung des GesamtIgA und dem Nachweis von IgAAntikörpern gegen tTG und EM. Bei positivem Befund schließt sich eine Dünndarmbiopsie im Rahmen einer Ösophagogastroduodenoskopie an.

\section{Remission unter glutenfreier Kost}

Zöliakie ist nicht heilbar, unter konsequenter glutenfreier Ernährung (z.B. Produkte von Dr. Schär), die lebenslang eingehalten werden sollte, bilden sich aber die klinischen, serologischen und intestinalen Befunde zurück.

Hinweis des Verlags. Der Verlag bleibt in Hinblick auf geografische Zuordnungen und Gebietsbezeichnungen in veröffentlichten Karten und Institutsadressen neutral.

J. Gastroenterol. Hepatol. Erkr. 2021 · 19:82 https://doi.org/10.1007/s41971-

021-00106-9

(c) Springer-Verlag GmbH Austria, ein Teil von Springer Nature 2021 